\title{
CAROTID BODY PARAGANGLIOMAS: CONTRIBUTION OF THE VARIOUS IMAGING TECHNIQUES. A REPORT OF NINE CASES
}

Authors: Dragos Catalin Jianu ${ }^{1 *}$, Silviana Nina Jianu ${ }^{2}$, Octavian Marius Cretu ${ }^{3}$, Flavius Traian Dan ${ }^{1}$, Georgiana Munteanu $^{1}$

\begin{abstract}
${ }^{1}$ Department of Neurology, "Victor Babes”" University of Medicine and Pharmacy, Timisoara, Romania
${ }^{2}$ Department of Ophthalmology, "Dr. Victor Popescu” Emergency Military Hospital, Timisoara, Romania

${ }^{3}$ Department of Surgery, "Victor Babeş" University of Medicine and Pharmacy, Timisoara, Romania;
\end{abstract}

"E-mail: dcjianu@yahoo.com

\section{BACKGROUND}

Carotid body paragangliomas (CBPGLs) are rare neoplasms of the neuroendocrine system that ffect the carotid glomus.

AIMS

To find specific clinical signs, and to compare the different imaging techniques, in order to elaborate a strategy for the management of CBPGLs.

\section{PATIENTS AND METHODS}

- This retrospective analysis reports family history, clinical presentation, imaging features, Shamblin classification, surgical treatment modalities, complications, and the outcome of nine patients with histopathological confirmed CBPGLs.

- All patients have been evaluated by extracranial duplex ultrasound as the first step, followed by a second group of examinations, represented by MRI and MR-A.

\section{RESULTS}

Clinical presentation.

- All unilateral CBPGLs were discovered upon patient self examination.

- The main clinical data are shown in table I.

- The first patient had a family history for CBPGL, and two different localizations (the second one was a glomus tumor of the right prelacrimal sac).

Table I. Clinical presentation of unilateral carotid body paraganglioma (CBPGL)

\begin{tabular}{|c|c|c|c|c|c|c|c|c|}
\hline $\mathbf{P t}$ & $\begin{array}{c}\text { Site/size: (cm) } \\
\text { of the neck } \\
\text { mass } \\
\text { (MRI) }\end{array}$ & $\begin{array}{c}\text { Consistency } \\
\text { of the neck } \\
\text { mass }\end{array}$ & $\begin{array}{c}\text { Pulsatiliy } \\
\text { of the } \\
\text { neck } \\
\text { mass }\end{array}$ & $\begin{array}{c}\text { Functional } \\
\text { tumor }\end{array}$ & $\begin{array}{c}\text { Preope- } \\
\text { rative } \\
\text { local } \\
\text { compli- } \\
\text { cations }\end{array}$ & $\begin{array}{c}\text { Shamblin } \\
\text { classifica- } \\
\text { tion }\end{array}$ & $\begin{array}{c}\text { Post-opera- } \\
\text { tive local } \\
\text { complications }\end{array}$ & $\begin{array}{c}\text { Post } \\
\text { opera- } \\
\text { tive } \\
\text { TIA / } \\
\text { stroke }\end{array}$ \\
\hline 1 & right/ 4.1 & $\begin{array}{c}\text { pain } \\
\text { less }\end{array}$ & yes & no & no & stage II & no & no \\
\hline 2 & left/ 4.3 & $\begin{array}{c}\text { pain } \\
\text { less }\end{array}$ & yes & no & no & stage II & no & no \\
\hline 3 & left/ 4.2 & $\begin{array}{c}\text { pain } \\
\text { less }\end{array}$ & yes & no & no & stage II & no & no \\
\hline 4 & right/ 4.2 & $\begin{array}{c}\text { pain } \\
\text { less }\end{array}$ & yes & no & no & stage II & no & no \\
\hline 5 & left/4.4 & $\begin{array}{c}\text { pain } \\
\text { less }\end{array}$ & yes & no & no & stage II & no & no \\
\hline 6 & right/ 4.1 & $\begin{array}{c}\text { pain } \\
\text { less }\end{array}$ & yes & no & no & stage II & no & no \\
\hline 7 & left/ 5.0 & $\begin{array}{c}\text { pain } \\
\text { less }\end{array}$ & yes & no & no & stage II & yes & no \\
\hline 8 & left/ 3.0 & $\begin{array}{c}\text { pain } \\
\text { less }\end{array}$ & yes & no & no & stage II & no & no \\
\hline 9 & right/4.0 & $\begin{array}{l}\text { pain } \\
\text { less }\end{array}$ & yes & no & no & stage II & yes & no \\
\hline
\end{tabular}

\section{$\underline{\text { Imaging diagnostic }}$}

\section{1). Duplex ultrasound characteristics:}

The topographic relation of the tumors to the carotid arteries and the internal jugular vein and the patterns of vascularization were assessed in all nine cases.

a). B-scan imaging

- A well-defined, solid, inhomogeneous, hypoechoic mass, located at the carotid bifurcation, that pushed the carotid arteries apart.

\section{b) Pulsed Doppler analvsis of blood flows}

- Low-resistance flow patterns (with a low RI, and a high diastolic component), obtained from multiple sites within the mass of the tumor.

- An arterio-venous shunt, with accelerate and turbulent flow in the vessels of the tumor.

c) The color Doppler imaging

- A characteristic broadening (wide splaying) of the carotid bifurcation by a hyper-vascular mass (the highly vascularized tumor), with shifting of both the ICA and the internal jugular vein posterior and laterally and of the ECA anterior and medially.

All CBPGLs could be assessed to their full extent (figure 1).

d) Power Doppler ultrasonography

- A intra-tumoral increased vasculature as an abundant flow, characterized as an intense blush pattern, throughout the entire tumor, mainly in small blood vessels.

- The ECA, and ICA were noted to surround the highly vascularized tumor.

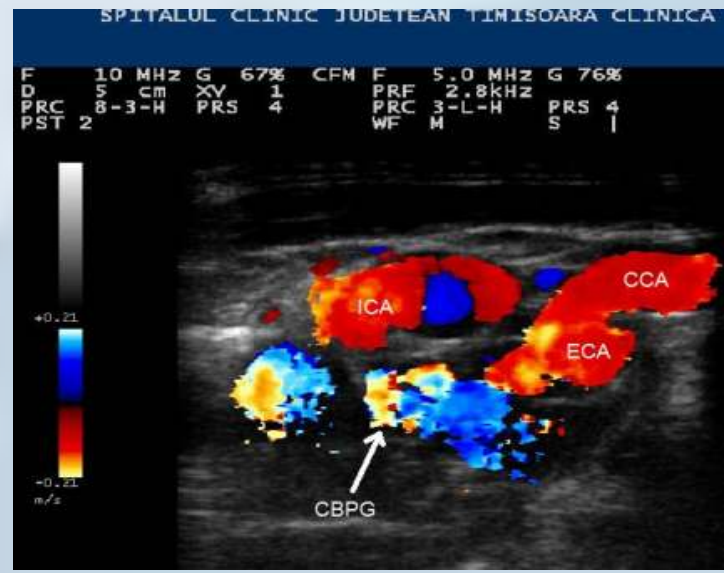

Figure 1. Duplex ultrasound - longitudinal view: carotid body tumor at right carotid bifurcation. Hypervascular cervical mass widening the right carotid bifurcation (the internal and external carotid arteries are separated by the tumor; accelerated and turbulent flow in the vessels of the tumor). CCA-common carotid artery; ICA-internal carotid artery; ECA-external carotid artery; CBTcarotid body tumor.

\section{2).MRI/MR-A characteristics:}

a) MRI indicated the full extent of the tumors and provided information about the absence of infiltration of adjacent structures in all cases, allowing us to assess the entire extent of all CBPGs.

- A densely enhanced tumor at a widened carotid bifurcation (all patients).

- The lesions were of intermediate intensity on T1-weighted images and slightly hyperintense on T2-weighted images (typical "salt and pepper" aspect) (four patients). (figure 2).

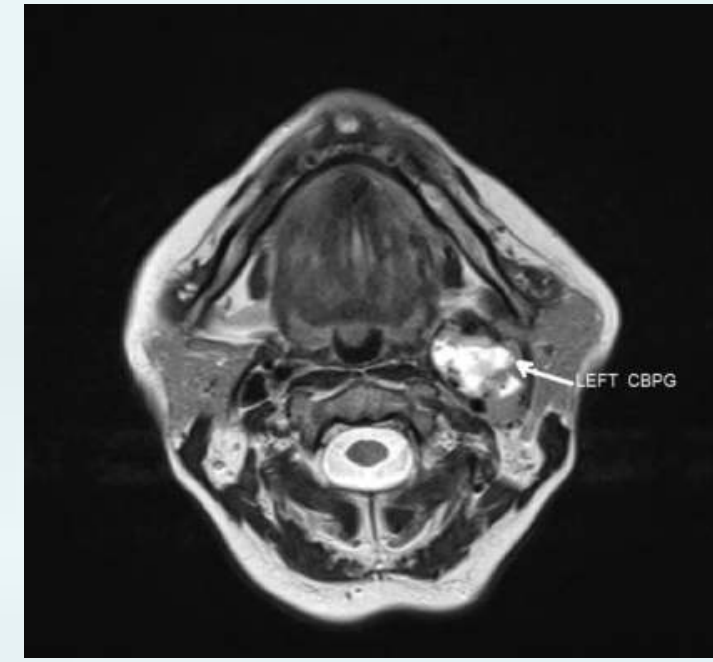

Figure 2. MRI of neck-Axial $T_{2}$-weighted images after Gadolinium: carotid body tumor at left carotid bifurcation. Hypervascular carotid space mass (arrow) splaying the internal and external carotid arteries. Typical "salt and pepper" aspect with prominent vascular flow voids.

b) MR-A confirmed the diagnosis, demonstrating a hyper-vascularized tumor in the carotid bifurcation.

- Splaying of the carotid bifurcation, with the ECA displaced anteriorly and the ICA and interna jugular vein located posteriorly (figure 3).

All CBPGLs derived their blood supply from the ECA

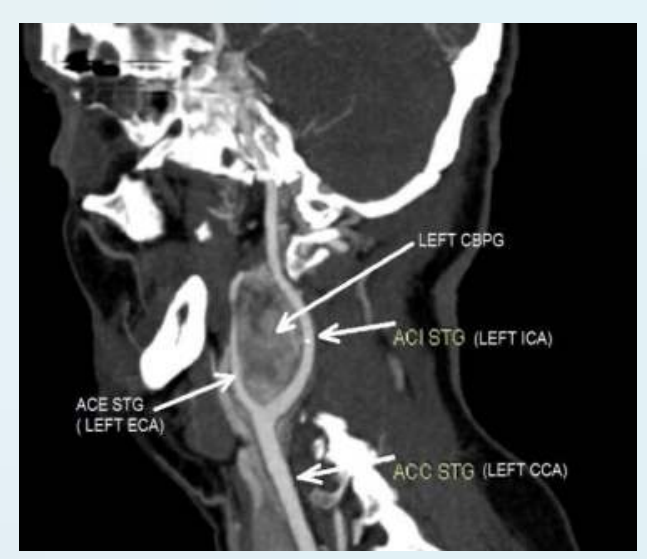

Figure 3. Angio-MRI (MR-A) of neck-Coronal view: carotid body tumor at left carotid bifurcation. Typical pattern of a CBPGL with splaying of the carotid bifurcation.

Using the preoperative imaging techniques, all neck tumors were classified into group II (3-5 $\mathrm{cm})$ according to their diameter.

- No lymph node metastasis was found at preoperative imaging in any of the cases.

\section{$\underline{\text { Surgical treatment }}$}

- No preoperative embolization was used in any of the cases.

Intra-operatively, on exploration of the neck, all patients showed CBPGLs group II Shamblin (tumors of medium size, with a latero-lateral diameter: $3-5 \mathrm{~cm}$, that partially surrounded the carotid vessels or adherent to them)

- We proceeded to a complete sub adventitial resection of the tumour in all cases.

- No lymph node involvement was found intra-operatively in any of the cases.

- Macroscopically, all CBPGLs resected were well circumscribed, rubbery and reddish brown

\section{The histological examination}

- The CBPGLs were confirmed in each case on histopathology (figure 4) and immunohistochemistry, where all the tumor cells tested positive for synaptophysin and chromogranin, negative for cytokeratin

- They showed no signs of malignancy in any of the cases.

- All resected lymph nodes resulted negative for metastasis at histological examination.
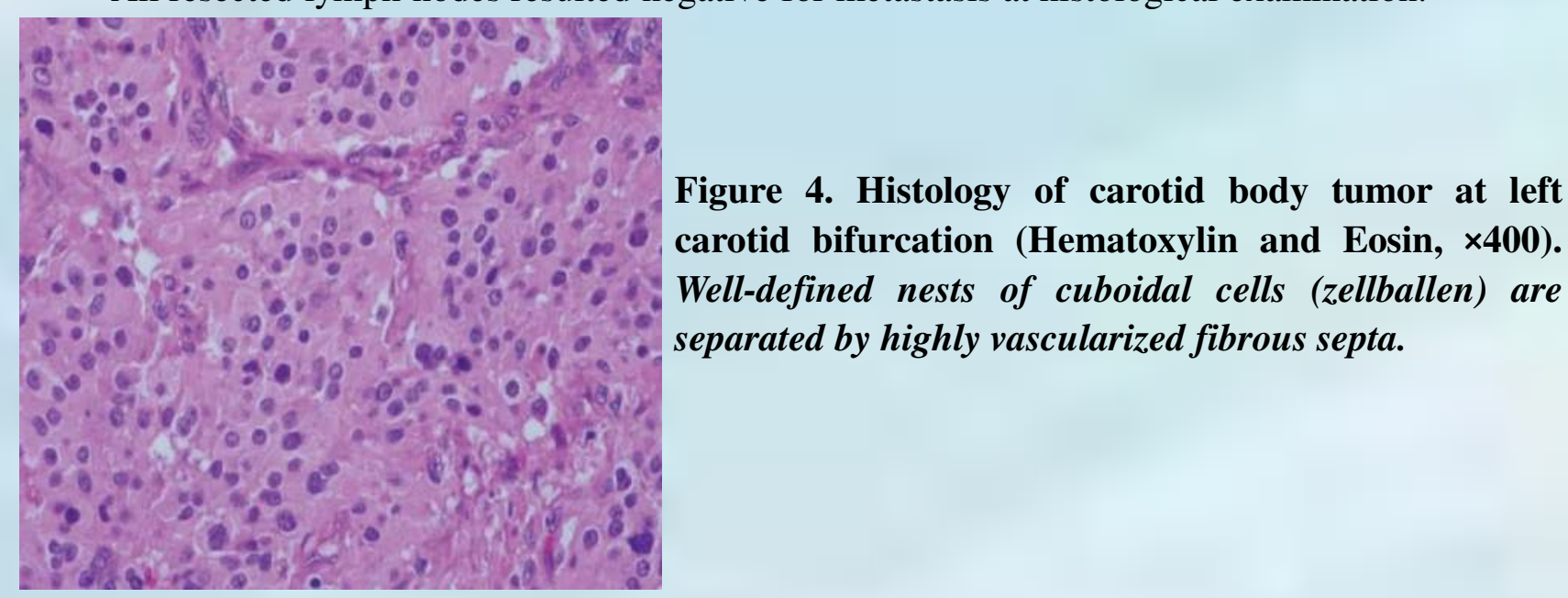

Surgical complications, and outcomes

- There was no operative mortality, and no peri-operative stroke/TIA were observed.

- No revision was needed for bleeding (no major bleeding/vascular injury were noted).

- The operating time was $123 \pm 20$ minutes.

- No post-operative complications (respiratory failure, hematoma, infection, or cranial nerve injury) were noted in eight cases.

- The 9th patient presented a transient ipsilateral vague nerve deficit (the tumor was tightly adherent to the neighboring vagus and was successfully resected sparing the nerve, but postoperatively the patient complained of dysphonia). Complete recovery was seen in her case after 3 months.

- After a follow-up of three years in each patient, there were no signs of tumor recurrence in any of the cases.

CONCLUSIONS

- Relatively early diagnosis of CBPGL was possible in all patients using multidisciplinary management.

- Preoperative planning of the surgical procedure by integrated diagnostic imaging was essential in our study to operate only Shamblin group II tumors, minimizing the known risk of complications associated with large CBPGL (group III). 